\title{
The relationship between player's gaming orientation and avatar's capital: A study in Final Fantasy XIV
}

\author{
Henry Korkeila \\ Gamification Group \\ Tampere University of Technology \\ \& University of Turku \\ henry.korkeila@tut.fi
}

\author{
Juho Hamari \\ Gamification Group \\ Tampere University of Technology \\ \& University of Turku \\ juho.hamari@tut.fi
}

\begin{abstract}
This study investigates the relationship between player's gaming orientation (dimensions of achievement, immersion and social orientation) and avatar's capital (social, economic, cultural and symbolic). The data was gathered through an online survey ( $n=905)$ amidst players of a MMORPG, Final Fantasy XIV. The results show that avatar's cultural capital is predicted by immersion orientation (customization, discovery, and role-playing), achievement orientation (mechanics) and social orientation (relationship and socializing). Economic capital is predicted by achievement orientation (advancement, competition, and mechanics) and social orientation (relationship and teamwork). Social capital was predicted by social orientation (relationship, socializing and teamwork) and immersion-orientation (escapism and customization). Symbolic capital was predicted by achievement orientation (advancement, competition, mechanics) and social orientation (relationship and teamwork).
\end{abstract}

\section{Introduction}

The popularity of video games is increasingly visible in everyday life in contemporary societies around the world. There are more games and gameful interactions available than ever before, and the gamification / ludification of our culture does not seem to be slowing down. [20][34]. The wider availability of the Internet and digitalization on a global scale has also dawned a phenomenon, what has been called as the exodus to virtual worlds [8] where people increasingly spend meaningful portions of their lives in virtual and game worlds. Players and their avatars can be seen to be living other lives in games; games that are outside the scope of what is traditionally understood to comprise our daily realities.
Naturally, the large bulk of research into games and players have focused on how games affect our "real lives", be it either through studies on problematic gaming (such as studies on addiction and aggression [23]) or the positive psychology related to games (such as studies on gamification - [16][34]). However, as games and virtual worlds are increasingly becoming a pertinent part of our lives, our investigation should also reach into outcomes relevant in the context of these worlds and not just on the outcomes the games have on our offline lives.

It has been postulated that games have a negative impact on our social and economic capital through the distance games drive between us and our lives [19][40]. Moreover, the cultural capital stemming from our experience within games have mostly been scoffed at as part of the geek culture - even though also efforts to normalize this form of capital has been initiated (see [11] on gaming capital).

However, efforts to investigate peoples' capital within game and virtual worlds, are currently scarce. Thus far, only social capital has been extensively studied in the context of virtual and game worlds (see e.g. [4][12][19][28][33][36]) and studies on players' other forms of capital in virtual worlds that use quantitative methods are rare.

In MMORPGs and virtual worlds, an avatar can be considered as a digitalized alter ego of the player. The capital the avatar has in-game and in-game communities bear varying amount of value outside the game and player communities related to it; in the so called "real world" (See [24] for a more elaborate discussion on this issue). For example, social capital in games can be accumulated by communicating with other players or being a part of organized groups. Economic capital is accumulated by collecting and saving in-game currencies and possessions. Cultural capital increases when the player gains knowledge of the game and uses it to advance his in-game endeavors, such as learning to be more effective at defeating monsters. Lastly, symbolic capital is amassed when the player earns a title, for example. 
Studying and exploring the capital of an avatar in virtual worlds allows for a deeper level of understanding of the avatars and ultimately players that control them. Exploring the relationship between the player orientations and avatar's capital sheds more light to how the virtual worlds are being inhabited. This, in turn, increases our understanding of the effects of virtualization and digitalization of our everyday lives as we gain more information about the actions in virtual contexts.

Therefore, this study investigates the relationship between player gaming orientation (achievement, immersion and social orientation) and avatar capital (social, economic, cultural and symbolic). The data was gathered through an online survey $(\mathrm{n}=905)$ amidst players of Final Fantasy XIV.

\section{Theory}

\subsection{Capital}

The term, capital, has been in use in the English language for a long time and during which its general usage has changed and evolved from strictly being part of the production cycle to oft mean available and accumulated resources to an entity [6][31]. Nowadays, it is normal to add a prefix to clarify and give context to the term, such as social capital.

Currently, five different types of categories can be identified that narrow down and give more context to the term capital. The first category includes definitions where the capital is tied to another broader context, such as social capital, where the context of the usage of the term is at the societal level [17][29][30].

The second category includes definitions that are more precise terms which are still operating under broader uses of the term. For example, there are multiple types of social capital, but in this digital age, two common subcategories are popular. Bonding and bridging social capital that Putnam [29] first conceptualized and Williams [37] later applied the theory in the form of a survey. Cultural capital also has three subcategories, as presented and defined by Bourdieu [7]: embodied, objectified and institutionalized. Each of these mentioned subcategories approaches their parent capital term from different points of view without contradicting it but describing in more detail what they contain.

The third category can be seen to include definitions that combine multiple capital into one. One of the most common examples is human capital [3]. Human capital can be understood to include different amounts of social, cultural, symbolic and economic capital, as defined by
Bourdieu [7], that together operates as one capital in enabling labor produce value.

The fourth category is the definitions that extend other broad scale terms and definitions by adding more contexts. For Example, Mia Consalvo speaks of gaming capital in her book Cheating: Gaining advantage in Video Games. Gaming capital, according to Consalvo, is a term that extends cultural capital by adding information that transforms the cultural capital's concept to video game context [11]. Bourdieu [7] also approached his capital theories at the societal level, and thus it can be seen that Consalvo rather extends cultural capital, than creates a new form of capital.

The fifth and last category is to approach capital as interconnected to other capital. For example, symbolic capital as defined by Bourdieu [7] falls into this category. According to Bourdieu [7], symbolic capital is directly affected by one's social, economic and cultural capital. Symbolic capital one has, thus, varies depending on his position and status as part of society. Symbolic capital is accumulated when a person gains prestige or honor based on his actions. To do or gain something prestigious in terms of symbolic value, one commonly has to have high amounts of cultural or economic capital that are recognized by others (social capital). For example, winning a championship in a big eSportstournament earns the team or player symbolic capital as they are socially (within the eSports-scene) recognized as best where only skills and knowledge (cultural capital) matter.

The reason for focusing on Bourdieu's division is that he made clear distinctions between the forms of capital, even though they originally were separated from the purely economic point of view [7]. Bourdieu first defined three different forms of capital: social, economic and cultural capitals [6]. Bourdieu himself divided the cultural capital into three subtypes: embodied, objectified and institutionalized. Later he added symbolic capital to the list.

Most literature pertaining to capital stems from the work of Bourdieu's [7] way of categorizing capital in the area of game research. Sometimes a prefix is placed before stating the term capital, for example, "group social capital" [28] or "online social capital" [37] or changing it altogether, for example, "gaming capital" [11] to narrow the usage of the term to the specific context they are used in. Even though not all of these publications cite the Bourdieu's [7] work, they still use his classification of different capital. Bourdieu's [7] division of capital is a unique way of portraying multiple capital when exploring larger contexts, such as societies. This framework can be applied to online multiplayer video games, where each game has its own society with both formal and informal rules. For this reason, it is 
meaningful to use Bourdieu's [7] categorization and find how various aspects of capital manifest in games.

Capital related to games has been previously investigated in the contexts of generic player study [4][36], players' health and well-being with topics varying from signs of addiction to well-being through self-regulations [19][23][27][33] and bonding and bridging social capital theory by Putnam and all articles listed here utilize Williams' (2006) popularized survey in one way or another [33][40].

Even with the multitude of studies where capital and video games are discussed in unison, there has relatively little literature on player capital and especially in the area of quantitative research (see, e.g. [4][36][39][40]). A study by Walsh and Apperley [35] used Bourdieu's framework of four capital to ask students various questions about them as a gamer and how they view other gamers. They approached the students' gaming capital by stating that social capital is needed for the exchange of capital to happen. This, in turn, means that gamers do possess multiple types of capital [35] and one type of capital alone is not enough to fully understand players or their actions regarding video game contexts.

\subsection{Player orientation scales}

There exists various player motivation and orientations scales, from granular player motivation measurement instruments such as BrainHex [26], a neurobiological gamer typology, to Trojan Player typology [22] and Game Experience Questionnaire [21]. Much of the player orientation measurement has been based on the works of Yee [38].

Yee's scale includes 39 items that were generated based on Bartle's [2] player types and qualitative information from previous MMORPG player surveys. Factor analysis revealed a total of ten motivations for play that were grouped under three main components, achievement, social, immersion. The subcomponents under achievement are advancement (the desire to gain power, progress and accumulate in-game wealth or status), mechanics (interested in analyzing and studying game's underlying rules and systems) and competition (the desire to challenge and compete with other players). The social main component includes socializing (interested in helping and chatting with other players), relationship (the desire to form meaningful relationships with other players) and teamwork (deriving satisfaction from being part of a group effort) subcomponents. Immersion houses discovery (finding and knowing things that most other players don't know about), role-playing (creating a persona with a background story and interacting with other players incharacter), customization (interested in editing the appearance of the avatar) and escapism (using the online environment to avoid thinking about offline life problems). Figure 1 depicts the research model of the study.

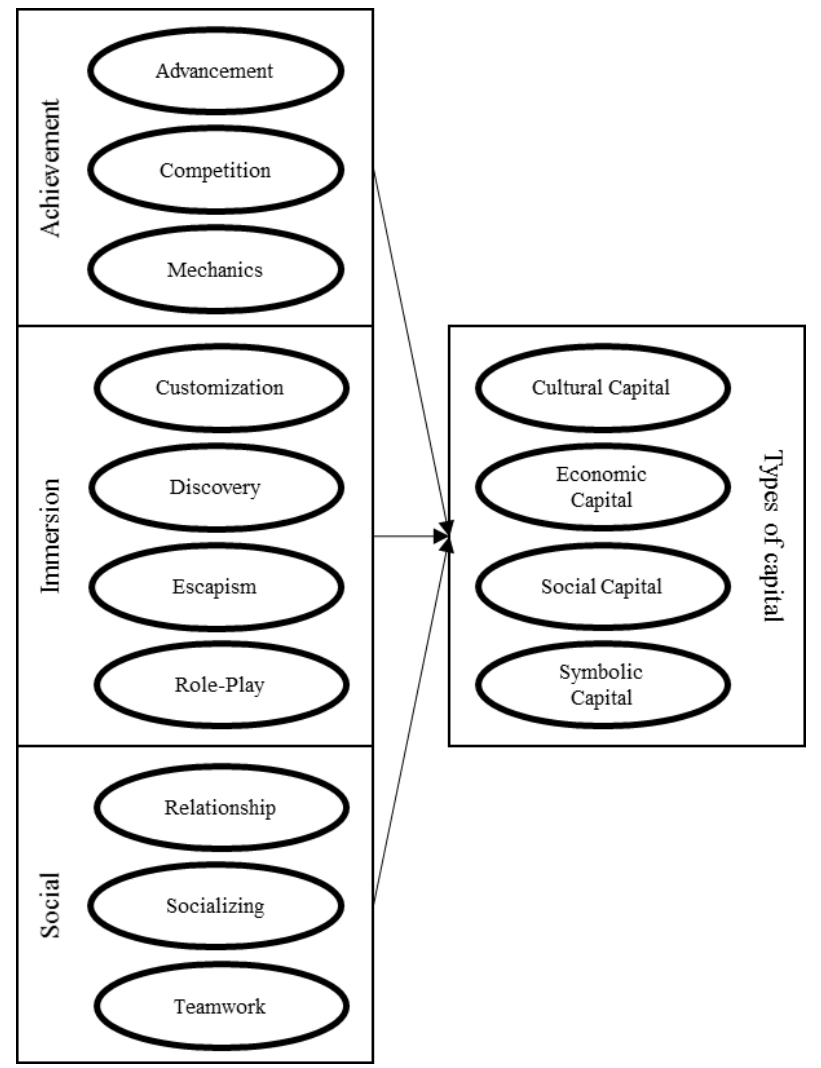

Figure 1. Simplified research model

\section{Methods and data}

\subsection{Measurement}

An online survey was conducted amidst players of Final Fantasy XIV (N=905). The survey was administered through SurveyGizmo online questionnaire tool. The survey took approximately 20 to 25 minutes for participants to fill.

Final Fantasy XIV (FFXIV) was originally launched in 2010 by Square Enix. FFXIV is a MMORPG that bears many resemblances to other Final Fantasy games, such as in form of similar monsters, familiar names, style of narrative, character development and descriptions of classes and jobs. FFXIV follows the steps of World of Warcraft and other MMORPGs in multiple ways. Players assume a role of an adventurer that travels around the continent to complete heroic deeds and help those who are in need. Gameplay is heavily story-driven, as is the case with Star Wars: The Old Republic (BioWare 2011) and Guild Wars 2 (ArenaNet 2012). Players of FFXIV were chosen on the 
basis of the data as the authors have a peep prior experience and knowledge about FFXIV which ensured greatly more valid operationalization of capital. Moreover, FFXIV is rather representative of a typical MMORPG game sharing multiple similarities to other large MMORPGs: e.g. the subscription model, "holy trinity" of roles, vertical character progression, expansions, level caps etc.

Existing measurement instruments were employed [37][38] to measure social capital and player's gaming orientation. For measuring avatar capital (or capital more generally), there are currently no standardized and validated measurement instruments for other forms of capital than social capital [37]. Therefore, measurement items for cultural, economic and symbolic capital were developed by the authors based on hundreds of hours and three years of experience with FFXIV.

The social capital was measured via an adjusted version of Williams' [37] online social capital scale. Adjustments were made to the scale to measure social capital within the context of FFXIV. Two items were omitted because they do not have a comparable in-game manifestation, as those items were related to real-life currency. As currencies in FFXIV are purely digital and in effect inside the game, and thus have no effect on offline life. After omitting two items from Williams' scale, a total of 18 items were remaining to measure social capital.

The economic capital, cultural capital and symbolic capital sections' items were formulated by the authors. Economic capital was measured, using 22 items, how much a player possesses economic assets and resources, spends and gains different currencies (in FFXIV in the form of gil, the game's main currency, or changeable to it directly or indirectly with one step in the middle at most).

Cultural capital measured player's knowledge of FFXIV from various points of view following definitions of cultural capital by Bourdieu [7] and in what ways the player possibly shares the gained knowledge to others. This included items that measured the respondent's knowledge and understanding of the game's functionalities, mechanics, lore and the amount of achievement points he had. This was accomplished with 16 items.

Symbolic capital was operationalized to measure the legitimization of other capital, such as recognition ingame through various feats. The 20 items included the ownership of rare mounts, pets or titles and if the avatar is recognized in the server by other players through gear, titles, avatar's name, behavior, achievements, for example. For the measurement items for the study, please see the supplementary material.

\subsection{Participants}

Players of FFXIV were recruited through official forums' English speaking section, a subreddit dedicated to FFXIV, a Discord (a program that combines VoIP chat with group instant messaging functionalities) server dedicated to FFXIV and three different Facebook groups dedicated to FFXIV: global, where players of FFXIV come together from all around the globe to share their feedback, and talk about various topics related to FFXIV; a group for Nordic players of FFXIV; and finally, a group for Finnish FFXIV players. Each group's moderators or admins were contacted beforehand and asked for permission to post the survey. After posting about the survey its visibility depended upon the functionalities of how each platform handles posting. In official forums, always the threads with latest posts are on the front page for more visibility, whereas in Facebook groups and Reddit, a thread's or post's visibility is depending upon the amount of posting and reactions (e.g. "liking" the post or up/downvoting the thread) within a certain timeframe. Discord's text chat functions much like traditional IRC, always the newest posts are visible at the bottom, otherwise, users must scroll up to see older posts.

The survey was open from March 16th to April 14th. At the time of closing the survey, there was a total of 1002 completed responses and after cleaning up the data, a total of 905 completed answers remain. A total of 711 out of $905(78.5 \%)$ answers had their source page listed. 212 people were redirected from Facebook, 215 from Reddit and 284 came from official forum links. Missing 194 sources could be from Discord-program, shared links (direct link to survey in a text form) or for some reason not-traceable.

The majority of respondents were male, 574 out of $905(63.4 \%)$. The average age of respondents was 27.2 $($ StdDev $=6.0 ;$ Median $=26)$, with the youngest being 14 and the oldest 55 years old. Almost half of all respondents were from USA (447, 49.3\%), United Kingdom $(91,10 \%)$ and Canada $(90,9.9 \%)$ following next. Other larger represented countries were Germany $(40,4.4 \%)$ and Finland $(31,3.4 \%)$ and the rest of the countries comprising $22.7 \%$ of the answers. In similar fashion, almost two-thirds $(599,66.1 \%)$ of respondents reported playing on the North American data center, while 274 (30.2\%) played on the European data center with a minority of players on Japanese data center. A bit over half were employed, either full-time (363 responses, $40.10 \%)$ or part-time (99 responses, $10.90 \%), 244(26.90 \%)$ were students, with 144 $(15.90 \%)$ were unemployed and rest of the players were disabled, retired, stay at home parents, or working alongside studies. A large majority of players were playing using PC $(675,74.5 \%)$ and PlayStation 4 (224, 
$24.7 \%)$. An extremely small minority of players were playing using a Mac $(2,0.2 \%)$ with a total of $5(0.6 \%)$ playing on the PlayStation 3. Over $80 \%$ (750 out of 905) of respondents placed themselves on a left-right axis to be in the centre-left area. Similarly, over 85\% (785 out of 905), on a conservative-liberal axis, stated they think to be in the middle-liberal area.

Over a fifth of respondents $(204,22.50 \%)$ were at veteran rank 13, implying they have been subscribed to FFXIV for at least three years and 92 (10.20\%) are at the current maximum veteran 14 , which requires being subscribed for four years. This is possible because players are able to pay subscription fees up to 6 months beforehand. FFXIV was re-released three years and eight months ago at the end of August 2013. Other veteran ranks had more even representation. Respondent spends almost 25 hours on average playing FFXIV in a seven-day period. However, half of the players reported playing between 11 and 30 hours per week, with four categories included (divided into 5-hour sections) having almost identical representation, ranging from $12.00 \%$ to $13.80 \%$ of answers. This high number of in-game active hours and veteran rank was further mirrored in the activity regarding FFXIV themed social media channels, as the vast majority (636, $70.20 \%$ ) reported visiting these sites at least couple times a week ("Almost daily" answer).

The majority of in-game avatars created were female $(540,59.60 \%)$, which means that to some degree male players were playing as a female character. Also, felinelike race, Miqo'te, was the most popular race with 292 $(32.20 \%)$ avatars, followed by human-like race, Hyur, with 183 avatars and horned and scaled race, $\mathrm{Au} \mathrm{Ra}$, with 183 avatars. The child-like race, Lalafell, was played by $119(13.1 \%)$ players, with elf-like race, Elezen, had $79(8.70 \%)$ players and large, muscular race, Roegadyn, with a smallest representative sample of $50(5.50 \%)$ players.

\subsection{Analysis Methods}

The data was analyzed using component-based structural equation modeling (in SmartPLS 3.0 program) [25][32] which is suitable for prediction oriented studies and when research model includes both reflective latent variables and formative variables [14].

\subsection{Validity and Reliability}

To assess the convergent validity for each latent variable, the average variance extracted (AVE) and composite reliability (CR) were calculated. AVE value should be greater than 0.5 to indicate the convergent validity and the $\mathrm{CR}$ value for reliability should surpass
0.7 [13]. It can be concluded the convergent validity was met. Table 1 shows the CR and AVE analysis results for variance and reliability. As CR and AVE are not applicable for formative constructs, variance inflation factors (VIF) were further calculated for each item of the formative constructs to assess validity. VIF-values are recommended to remain under the threshold of 5 [32]. All values were lower than 2.

Table 1. Composite Reliability and AVE

$\begin{array}{lccc}\text { Achievement } & \text { Items } & \text { CR } & \text { AVE } \\ \text { Advancement } & 5 & 0.833 & 0.500 \\ \text { Competition } & 4 & 0.783 & 0.555 \\ \text { Mechanics } & 3 & 0.858 & 0.602 \\ \text { Immersion } & & & \\ \text { Customization } & 3 & 0.851 & 0.657 \\ \text { Discovery } & 4 & 0.872 & 0.631 \\ \text { Escapism } & 3 & 0.822 & 0.608 \\ \text { Role-Playing } & 4 & 0.831 & 0.554 \\ \text { Social } & & & \\ \text { Relationship } & 3 & 0.895 & 0.740 \\ \text { Socializing } & 4 & 0.884 & 0.658 \\ \text { Teamwork } & 4 & 0.892 & 0.805 \\ \text { Capital } & & & \\ \text { Cultural } & 16 & \text { na } & \text { na } \\ \text { Economic } & 22 & \text { na } & \text { na } \\ \text { Social } & 18 & 0.926 & 0.512 \\ \text { Symbolic } & 20 & \text { na } & \text { na }\end{array}$

To assess discriminant validity, Fornell-Larcker criterion and heterotrait-monotrait (HTMT) values were calculated (Table 2). To satisfy the Fornell-Larckercriterion, the correlation between a construct and every other construct must be less than the square root of AVE for said construct (bolded figures on the diagonal). To satisfy the heterotrait-monotrait criterion, each value must be less than 0.85 [18]. It can be concluded that discriminant validity was met. HTMT discriminant validity assessment only applies to reflective consorts, and therefore, formative constructs (cultural, economic and symbolic capital) are not displayed in the Table 2 shows the HTMT criterion values.

The filtered sample size of 905 respondents greatly exceeds lower limits for minimum recommended sample size. A model that has constructs with three to four items, minimum of 150 respondents is needed for validity [1]. Bentler and Chou [5] propose a much 
stricter minimum number of respondents, five cases per observed variable. In this study, that number would be 555 respondents.

\section{Results}

The player's gaming orientations accounted for $54.3 \%$ of the variance for cultural capital, $20.7 \%$ for economic capital, $58.5 \%$ for social capital and $33.1 \%$ for symbolic capital. Cohen [10] suggested that if $\mathrm{R}^{2}$-value is over 0.26, the variance explained is substantial, moderate if the value is over 0.13 and weak for values over 0.02 . Thus, the $\mathrm{R}^{2}$-values for the forms of capital each explained a substantial amount of variance.

Table 3 illustrates full results with significant association values bolded.

Pertaining to the relationship between player orientations and cultural capital of the avatar it was found that achievement-mechanics ( $\mathrm{Ha} 2 \beta=0.144^{* *}$ ), immersion-customization $\left(\beta=0.245^{* *}\right)$, immersion- discovery (Hi1 $\beta=0.181^{* *}$ ), immersion-role-playing $\left(\right.$ Hi2 $\left.\beta=0.335^{* *}\right)$, social-relationship $\left(\beta=0.100^{* *}\right)$ and social-socializing $\left(\beta=0.077^{*}\right)$ were associated with cultural capital.

Economic capital was found to be associated with achievement-advancement $\left(\beta=0.109^{* *}\right)$, achievementcompetition $\left(\beta=0.144^{* *}\right)$, achievement-mechanics $(\beta=$ $\left.0.187^{* *}\right)$, social- relationship $\left(\beta=0.095^{*}\right)$ and socialteamwork $\left(\beta=0.093^{*}\right)$ player orientations.

Social capital was found to be associated with immersion-escapism $\left(\beta=0.073^{* *}\right)$, immersion-roleplaying $\left(\beta=-0.053^{*}\right)$, social-socializing (Hs1 $\beta=$ $\left.0.325^{* *}\right)$, social-relationship (Hs2 $\beta=0.433^{* *}$ ) and social-teamwork (Hs3 $\left.\beta=0.091^{* *}\right)$.

Symbolic capital was found to be associated with achievement-advancement (Ha1 $\beta=0.161 * *)$, achievement-competition $\left(\beta=0.106^{* *}\right)$, achievementmechanics $\left(\beta=0.098^{*}\right)$, social-relationship $(\beta=$ $0.327 * *)$ and social-teamwork $\left(\beta=0.175^{* *}\right)$.

Table 2. Heterotrait-monotrait values \& Fornell-Larcker criterion (square roots of AVE bolded)

\begin{tabular}{|c|c|c|c|c|c|c|c|c|c|c|c|c|c|c|}
\hline & 1 & 2 & 3 & & 4 & 5 & 6 & 7 & & 8 & 9 & 10 & & 11 \\
\hline $\begin{array}{l}1 \text { Advancement } \\
2 \text { Competition }\end{array}$ & 0.705 & & & & & & & & & & & & & \\
\hline 3 Mechanics & 0.774 & 0.573 & & & & & & & & & & & & \\
\hline 4 Customization & 0.298 & 0.121 & 0.166 & & & & & & & & & & & \\
\hline 5 Discovery & 0.181 & 0.063 & 0.066 & & 499 & & & & & & & & & \\
\hline 6 Escapism & 0.190 & 0.074 & 0.109 & & 327 & 0.315 & & & & & & & & \\
\hline 7 Role-Playing & 0.210 & 0.100 & 0.145 & & 04 & 0.632 & 0.554 & & & & & & & \\
\hline 8 Relationship & 0.233 & 0.235 & 0.160 & & 37 & 0.309 & 0.366 & 0.426 & & & & & & \\
\hline 9 Socializing & 0.224 & 0.252 & 0.158 & & 38 & 0.449 & 0.372 & 0.473 & & 0.611 & & & & \\
\hline 10 Teamwork & 0.355 & 0.281 & 0.397 & & 69 & 0.126 & 0.112 & 0.147 & & 0.446 & 0.579 & & & \\
\hline 11 Social Capital & 0.274 & 0.250 & 0.163 & & 55 & 0.325 & 0.370 & 0.351 & & 0.767 & 0.726 & 0.505 & & \\
\hline & 1 & 2 & 3 & 4 & 5 & 6 & 7 & 8 & 9 & 10 & 11 & 12 & 13 & 14 \\
\hline 1 Advancement & 0.707 & & & & & & & & & & & & & \\
\hline 2 Competition & 0.512 & 0.745 & & & & & & & & & & & & \\
\hline 3 Mechanics & 0.593 & 0.432 & 0.776 & & & & & & & & & & & \\
\hline 4 Customization & 0.217 & 0.082 & 0.126 & 0.810 & & & & & & & & & & \\
\hline 5 Discovery & 0.090 & 0.014 & -0.002 & 0.401 & 0.794 & & & & & & & & & \\
\hline 6 Escapism & 0.103 & 0.026 & -0.021 & 0.233 & 0.229 & 0.780 & & & & & & & & \\
\hline 7 Role-Playing & 0.058 & 0.028 & -0.021 & 0.365 & 0.477 & 0.383 & 0.745 & & & & & & & \\
\hline 8 Relationship & 0.196 & 0.196 & 0.140 & 0.270 & 0.259 & 0.271 & 0.331 & 0.860 & & & & & & \\
\hline 9 Socializing & 0.152 & 0.125 & 0.068 & 0.262 & 0.352 & 0.273 & 0.352 & 0.525 & 0.811 & & & & & \\
\hline 10 Teamwork & 0.275 & 0.231 & 0.305 & 0.134 & 0.066 & 0.062 & 0.099 & 0.367 & 0.488 & 0.897 & & & & \\
\hline 11 CCapital & 0.239 & 0.103 & 0.196 & 0.525 & 0.508 & 0.331 & 0.590 & 0.399 & 0.401 & 0.200 & NA & & & \\
\hline 12 ECapital & 0.352 & 0.321 & 0.367 & 0.182 & 0.047 & 0.043 & 0.026 & 0.190 & 0.095 & 0.229 & 0.187 & NA & & \\
\hline 13 SCapital & 0.228 & 0.206 & 0.136 & 0.294 & 0.281 & 0.291 & 0.281 & 0.676 & 0.633 & 0.431 & 0.478 & 0.201 & 0.715 & \\
\hline 14 SyCapital & 0.386 & 0.331 & 0.342 & 0.202 & 0.136 & 0.075 & 0.098 & 0.429 & 0.248 & 0.368 & 0.330 & 0.308 & 0.462 & NA \\
\hline
\end{tabular}


Table 3: Results $\left(^{\star}=p<0.05,{ }^{\star *}=p<0.01\right.$, significant associations bolded)

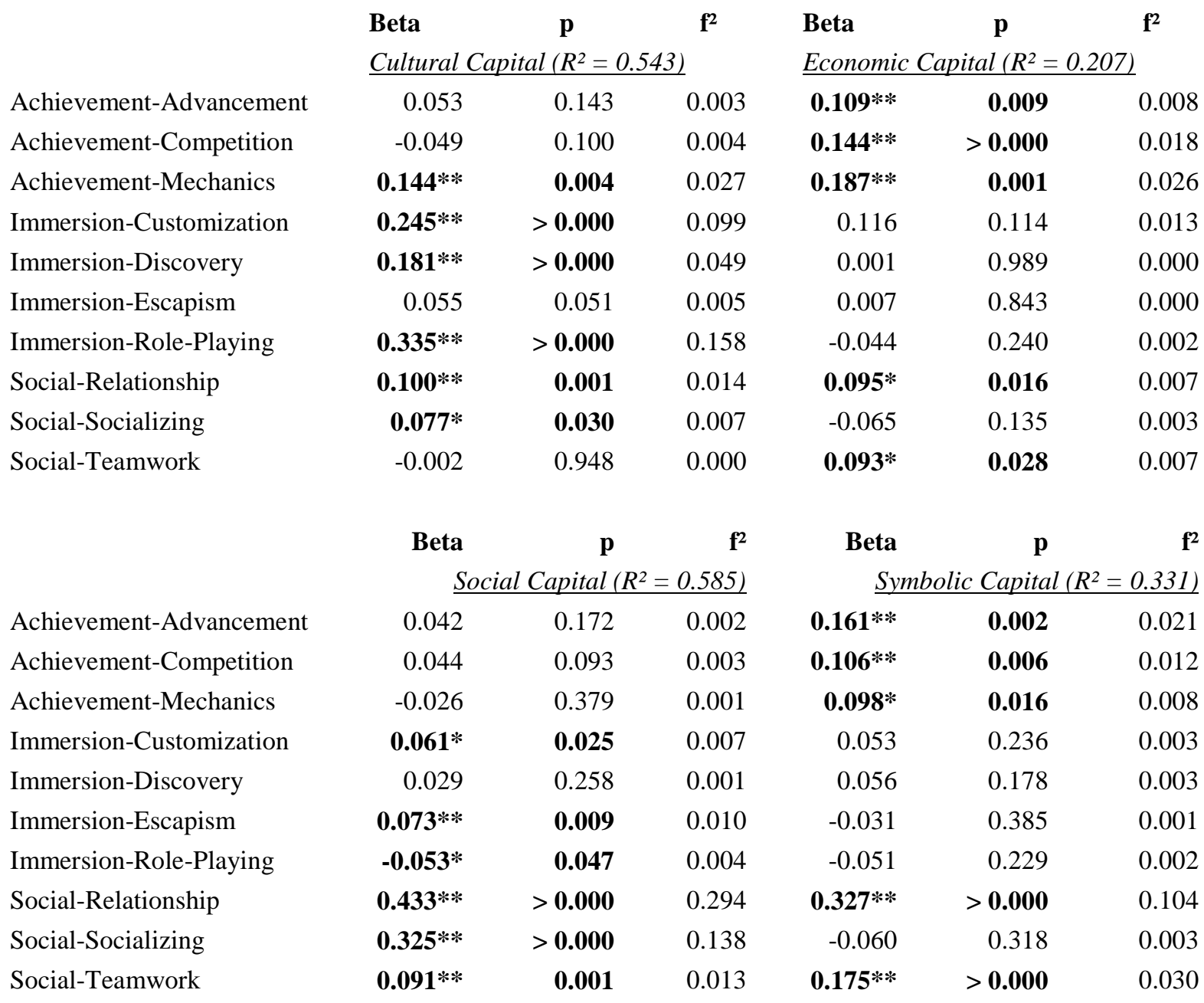

\section{Discussion, limitations, future work}

This study had to primary contributions; 1) developing a measurement instrument of avatar capital that expanded the current measurement with economic, cultural and symbolic capital, and, 2) shedding light on the relationship between player orientation and avatar capital. The development of the measurement instrument will continue and will be further elaborated in further studies.

The findings indicate that the all dimensions of the player orientation instrument were associated with at least one form of avatar capital. This indicates that the player orientations seem to be highly relevant for determining avatar capital which also lend support for wider applicability and relevance of considering player orientations as background variables in predicting player behavior.
Cultural capital is strongly associated with discovery-orientation which may suggest that for the accumulation of cultural capital, gameplay oriented towards actively seeking information about the game is important. Moreover, cultural capital is associated with orientation toward the mechanics of the game, customizing, socializing and role-playing that are likely to be important avenues for employing cultural capital.

Economic capital's positive association with achievement orientation subcomponents alludes that players with a focus on achieving in a game that includes avatar progression, understanding of the game's functions at the mechanic level and direct competition with other players do have a higher amount of economic capital on their avatars than players with a lower focus achieving status or progress. The positive association between economic capital and relationship and teamwork orientations 
indicates that closer and tighter communities might also be key for economic capital accumulation.

It is not surprising that each component of social gaming orientation as well as the role-playing orientation had a significant positive association with social capital. The positive association between social capital and escapism may indicate that players looking for escapism may also indicate that social play and play for relaxation may have a connection. Moreover, the association between social capital and customization-orientation hints customization being used as an avenue for social capital.

Lastly, symbolic capital, similarly to economic capital, is mostly connected to all achievementorientations but differs in magnitude in its connection with social orientations: symbolic capital is notably more strongly connected with relationship and teamwork-orientations which can be expected since symbolic capital is more defined through social interactions whereas economic capital can be more formally defined.

The results indicate that the amount of each capital an avatar has can be predicted simultaneously by multiple player orientation subcomponents. Furthermore, the scoring of each subcomponent and forms of capital are not mutually exclusive, meaning that a player with a high score in achievement subcomponents plays an avatar with high amounts of economic and symbolic capital. Similarly, a player with a high score in customization, role-play, relationship and socializing plays an avatar with high amounts of cultural and social capital. Additionally, relationship subcomponent was found to significantly associate with each form of capital and discovery and escapism was found to have just one positive association each.

The results promote the view that the formation of avatar capital is a complex phenomenon where avatars possess differing levels of multiple forms of capital and which also depend on their gaming orientation. These findings support Walsh and Apperley's [35] claim that players and gamers alike have multiple forms of capital in their possession. Only exceptions are Immersion-Discovery and -Escapism that each were found to have only one significant association. This finding does support the claim that focusing solely on social capital in MMORPG context is ultimately flawed way to study those inhabiting them. It should be noted that, for example, a player that is Achievement-oriented were not found to have significant association with avatar's social capital does not mean that the avatar has no social interactions within FFXIV. They just are not the focus for the player.
As this was the first-time capital in MMORPGs have been approached this widely, the way capital were presented in this study are not set in stone. It might be necessary to extend existing forms of capital or present new to fit the precise needs of avatar studies, much like what Consalvo [11] did with cultural capital. Bourdieu's [7] framework of capital was successfully transferred to purely virtual context. The way the framework was utilized was one step deeper the way Walsh and Apperley [35] utilized Bourdieu's [7] framework.

Moreover, games and other context have many specificities regarding terminology, therefore, measuring avatar capital on a granular level requires context-specific adjustments. For practitioners in the video game industry, this approach provides a powerful avenue to measure avatar's capital and how they are accumulated and consumed. This way the developers of video games can map out how the players of their games perceive their game in terms of coherence, affordances for social interactions, being recognized for their feats and so on. This brings issues with the ability to directly compare results between MMORPGs, and games within the same genre in general, but basic aspects should not prove too difficult. The game's mechanics and lore present challenges, as games have different battle, leveling and questing systems, and therefore, the accurate measurement these aspects per game may have to differentiate. Even though players' knowledge increases, it does so on in a form that is dependent on the game. This offers developers of these games a tool to further study their players and find possible reasons why some aspects of a game are used more than others, how the players use their time in the game and why.

The future efforts on the research on player capital should seek to further develop and validates the measurement in numerous other MMORPGs and other game genres.

As is commonplace with SEM-based studies, the survey data is cross-sectional, and therefore, inferences about the causality cannot be ascertained with certainty. However, our independent variables can be considered more static traits of players, whereas the dependent variables related to player capital can be assumed to fluctuate more rapidly. Therefore, it is reasonable to assume that player capital in any given game is more dependent on player orientation rather than the other way around. 


\section{Acknowledgements}

This work was supported by the Academy of Finland, the Finnish Funding Agency for Technology and Innovation (TEKES40111/14, 40107/14 and 40009/16) and participating partners, as well as Satakunnan korkeakoulusäätiö and its collaborators.

\section{References}

[1] Anderson, J. C. and D.W. Gerbing, "The effect of sampling error on convergence, improper solutions, and goodness-of-fit indices for maximum likelihood confirmatory factor analysis.", Psychometrika 49, 1984, pp. $155-173$.

[2] Bartle, R., "Hearts, clubs, diamonds, spades: Players who suit MUDs." 1996. http://mud.co.uk/richard/hcds.htm

[3] Becker, G.S., Human Capital: A Theoretical and Empirical Analysis, with Special Reference to Education (3rd ed.), University of Chicago Press, Chicago, 1993.

[4] Benefield, G.A., C. Shen and A. Leavitt, "Virtual Team Networks: How Group Social Capital Affects Team Success in a Massively Multiplayer Online Game.”, Paper presented at the Conference on Computer-Supported Cooperative Work and Social Computing, February 27 - March 2, 2016. [5] Bentler, P.M. and C-P. Chou, "Practical Issues in Structural Modeling.", Sociological Methods \& Research 16(1), 1987, pp. 18-117.

[6] Bourdieu, P., Distinction: A social critique of the judgement of taste, Harvard University Press, Cambridge, Massachusetts, 1984.

[7] Bourdieu, P., "The Forms of Capital" In Handbook of Theory and Research for the Sociology of Education, edited by J.G. Richardson, translated by R. Nice, Greenwood, New York, 1986, pp. 241-258.

[8] Castronova, E., Exodus to the Virtual World, Palgrave Macmillan, London, United Kingdom, 2007.

[9] Chin, W.W., "The partial least squares approach for structural equation modeling.", In Modern Methods for Business Research, edited by G.A. Marcoulides, Lawrence Erlbaum Associates, Mahwah, New Jersey, 1988, pp. 295336.

[10] Cohen, J., Statistical Power Analysis for the Behavioral Sciences (2nd ed.), Lawrence Erlbaum Associates, Hillsdale, New Jersey1988.

[11] Consalvo, M., Cheating: Gaining Advantage in Video Games, The MIT Press Cambridge, Massachusetts, 2007.

[12] Ducheneaut, N., N. Yee, E. Nickell and R.J. Moore, 2006. "Alone Together? Exploring the Social Dynamics of Massively Multiplayer Online Games.", In Proceedings of the 2006 Conference on Human Factors in Computing Systems, Montréal, Québec, Canada, April 22-27, 2006.

[13] Fornell, C. and D.F. Larcker, "Evaluating structural equation models with unobservable variables and measurement error.", Journal of Marketing Research 18(1), 1981, pp. 39-50.

[14] Hair, J. F., Jr., G. Thomas, M. Hult, C.M. Ringle and M. Sarstedt, A Primer on Partial Least Squares Structural
Equation Modeling (PLS-SEM), Sage, Thousand Oaks, California, 2014.

[15] Hair, J.F., Jr., C.M. Ringle and M. Sarstedt. "PLS-SEM: Indeed a silver bullet.", Journal of Marketing Theory and Practice, 19(2), 2011, pp. 139-151.

[16] Hamari, J., J. Koivisto, and H. Sarsa, "Does gamification work? - A literature review of empirical studies on gamification." In Proceedings of the 47th Annual Hawaii International Conference on System Sciences, Hawaii, USA, January 6-9, 2014.

[17] Hanifan, L.J., "The Rural School Community Center.", Annals of the American Academy of Political and Social Science 67, 1916, pp. 130-138.

[18] Henseler, J., C.M. Ringle and M. Sarstedt, “A New Criterion for Assessing Discriminant Validity in Variancebased Structural Equation Modeling.", Journal of the Academy of Marketing Science 43(1), 2015, pp. 115-135.

[19] Hsu, S.H., M-H. Wen and M-C. Wu, "Exploring user experiences as predictors of MMORPG addiction.", Computers \& Education 53, 2009, pp. 990-999.

[20] Huotari, K., and J. Hamari, "A definition for gamification: Anchoring gamification in the service marketing literature.”, Electronic Markets, 27(1), 2017, pp. 21-31.

[21] IJsselsteijn, W.A., Y.A.W. de Kort and K. Poels, The Game Experience Questionnaire, University of Technology of Eindhoven, Eindhoven, The Netherlands, 2013. https://pure.tue.nl/ws/files/21666907/Game_Experience_Q uestionnaire_English.pdf

[22] Kahn, A.S., C. Shen, L. Lu, R.A. Ratan, S. Coary, J. Hou, J. Meng, J. Osborn and D. Williams, "The Trojan Player Typology: A cross-genre, cross-cultural, behaviorally validated scale of video game play motivations.", Computers in Human Behavior 49, 2015, pp. 354-361.

[23] Kneer, J., M. Elson, and F. Knapp, "Fight fire with rainbows: The effects of displayed violence, difficulty, and performance in digital games on affect, aggression, and physiological arousal", Computers in Human Behavior 54, 2016, pp. 142-148.

[24] Lehdonvirta, V., "Virtual worlds don't exist: Questioning the dichotomous approach in MMO studies.", Game Studies, 10(1), 2010, pp. 1-14.

[25] Lowry, P. and J. Gaskin, "Partial Least Squares (PLS) Structural Equation Modeling (SEM) for Building and Testing Behavioral Causal Theory: When to Choose It and How to Use It", IEEE Transactions on Professional Communication 57(2), 2014, pp. 123-146.

[26] Nacke, L.E., C. Bateman and R.L. Mandryk, "BrainHex: preliminary results from a neurobiological gamer typology survey." Entertainment Computing 5, 2014, pp. 288-293.

[27] Nardi, B. and J. Harris, "Strangers and Friends: Collaborative Play in World of Warcraft.", In Proceedings of Computer Supported Cooperative Work, Banff, Alberta, Canada, November 4-8, 2006.

[28] Oh, H., M-H. Chung and G. Labianca, "Group social capital and group effectiveness: The role of informal socializing ties.", The Academy of Man-agement Journal 47, 2004, pp. 860-875. 
[29] Putnam, R.D., "Bowling alone: America's declining social capital.", Journal of Democracy, 6(1), The Johns Hopkins University Press, Baltimore, Maryland, 1995, pp. 65-78.

[30] Putnam, R. D., Bowling alone: The collapse and revival of American community, Simon \& Schuster, New York, 2000.

[31] Ra, E., "Understanding the Role of Economic, Cultural, and Social Capital and Habitus in Student College Choice: An Investigation of Student, Family, and School Contexts.", PhD diss., The University of Michigan, USA, 2011.

[32] Ringle, C.M., S. Wende and J-M. Becker, SmartPLS 3. Bön-ningstedt: SmartPLS, 2015. http://www.smartpls.com

[33] Shen, C. and W. Chen, "Social capital, coplaying patterns, and health disruptions: A survey of Massively Multiplayer Online Game participants in China.", Computers in Human Behavior 52, 2015, pp. 243-249.

[34] Vesa, M., J. Hamari, J.T. Harviainen and H. Warmelink. "Computer games and organization studies.", Organization Studies, 38(2), 2017, pp. 273-284.

[35] Walsh, C. and T. Apperley. "Gaming capital: Rethinking literacy." In: Changing Climates: Education for sustainable futures. Proceedings of the AARE 2008 International Education Research Conference, Queensland University of Technology, Australia, November 30 December 4, 2008,

[36] Williams, D., N. Ducheneaut, X. Li, N. Yee and E. Nickell, "From Tree House to Barracks: The Social Life of Guilds in World of Warcraft", Games and Culture 1, 2006, pp. 338-361.

[37] Williams, D., "On and Off the 'Net: Scales for Social Capital in an Online Era", Journal of Computer-Mediated Communication, 11, 2006, pp. 593-628.

[38] Yee, N., "Motivations of Play in Online Games.", Journal of CyberPsychology and Behavior, 9, 2007, pp. 772775 .

[39] Zhang, F. and D. Kaufman, "The impacts of social interactions in MMORPGs on older adults' social capital.", Computers in Human Behavior 51, 2015, pp. 495-503.

[40] Zhong, Z-J., "The effects of collective MMORPG (Massively Multiplayer Online Role-Playing Games) play on gamers' online and offline social capital.", Comput-ers in Human Behavior 27, 2011, pp. 2352-2363. 